\title{
O Teste do Desenho da Figura Humana em Crianças Angolanas: Contribuições à Perspectiva da Psicologia Positiva
}

\author{
Human Figure Drawing by Angolan Children \\ from a Positive Psychology Approach
}

La Prueba del Dibujo de la Figura Humana en Niños de Angola: Contribuciones para el Entendimiento de la Psicología Positiva

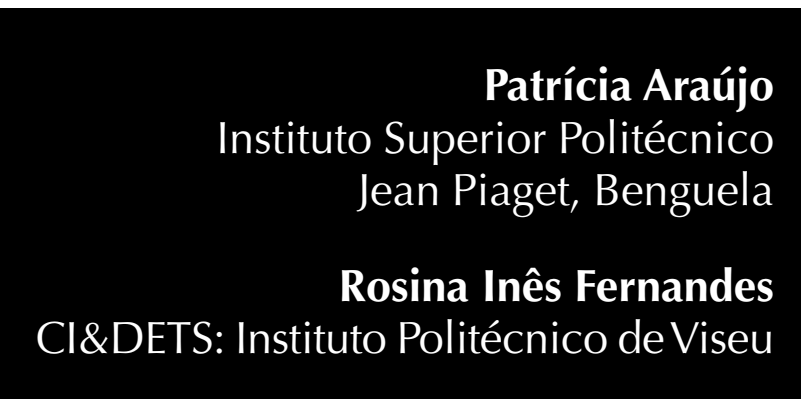

http://dx.doi.org/10.1590/1982-3703002132013 
Resumo: Angola é um país do continente africano, em franco desenvolvimento, no qual existem diversas dificuldades no acesso a recursos de avaliação e intervenção psicológica em geral, salientando-se a marcante escassez de instrumentos validados e aferidos para a população angolana. Por outro lado, como em muitos outros momentos históricos, o arranque da Psicologia neste país parece marcado por abordagens negativas do funcionamento humano. De fato, pode constatar-se a excessiva procura de psicopatologias, o que constitui um paradoxo pois são escassos os estudos sobre incidências, prevalências ou descrições para o psicodiagnóstico em Angola. Assim, com esta investigação, pretende-se refletir sobre o potencial de aplicação da prova de avaliação psicológica intelectual do Desenho da Figura Humana de Goodenough nesta população, tanto numa perspetiva de avaliação intelectual, como numa perspetiva mais abrangente e menos negativamente rotuladora de abordagem ao desenho infantil. Este estudo de caso múltiplo conta com aplicações do referido teste a seis crianças de nacionalidade angolana, com idades compreendidas entre os 6 e os 10 anos, residentes na província de Benguela. Espera-se contribuir para a reflexão acerca da sua aplicação em crianças deste país e ir mais além da mera aplicação como instrumento de avaliação, procurando explorar perspetivas inovadoras decorrentes da linha clássica humanista em geral, sensibilizando para novas abordagens no âmbito da recente psicologia positiva.

Palavras-chave: Desenho. Avaliação. Psicologia.

Abstract: Angola is a fully developed African country which faces several difficulties in accessing resources to proceed with psychological assessment and intervention in general, emphasizing the striking lack of validated instruments for the Angolan population. Moreover, like many other historical moments, the beginning of psychology in this country is marked by negative approaches to human functioning. In fact, an excessive demand for psychopathology is observed, which is a paradox because there are few studies on the incidence, prevalence, or description of psychodiagnostics in Angola. Therefore, with this research, we reflect on the potential application of the psychological assessment test of Human Figure Drawing by Goodenough in this population, both from the perspective of intellectual assessment and also as a broader and less negatively labeled approach to children's drawing. This case study describes multiple applications of the test in six children of Angolan nationality, aged 6-10 years, living in the province of Benguela, Angola. We expect to contribute to the debate about its use for children of this country and go beyond its mere application as an evaluation tool by exploring innovative perspectives arising from the classic line of humanist psychology and raising awareness of new approaches in the context of recent positive psychology.

Keywords: Design. Evaluation. Psychology.

Resumen: Angola es un país del continente africano en franco desarrollo, en el cual existen diversas dificultades en el acceso a recursos de evaluación e intervención psicológica en general, destacándose la enorme escasez de instrumentos validados para la población angolana. Por otro lado, como en muchos otros momentos históricos, el arranque de la psicología en este país parece marcado por entendimientos negativos del funcionamiento humano. De hecho, puede constatarse la excesiva búsqueda de psicopatologías, lo que constituye una paradoja pues son escasos los estudios sobre incidencias, prevalencias o descripciones para el diagnóstico psicológico en Angola. Así, con esta investigación, se pretende reflexionar sobre el potencial de aplicación de la prueba de evaluación psicológica intelectual del Dibujo de la Figura Humana de Goodenough en esta población, tanto en una perspectiva de evaluación intelectual, como en una configuración más amplia y menos negativamente rotuladora del abordaje del dibujo infantil. Este estudio de caso múltiple cuenta con aplicaciones de la referida prueba a seis niños de nacionalidad angolana, con edades comprendidas entre los 6 y los 10 años, residentes en la provincia de Benguela. Se espera contribuir para la reflexión acerca de su aplicación en niños de este país e ir más allá de la mera aplicación como instrumento de evaluación, buscando explorar perspectivas innovadoras decurrentes de la línea clásica humanista en general, sensibilizando para nuevos entendimientos en el ámbito de la reciente psicología positiva.

Palabras clave: Diseño. Evaluación. Psicología. 


\section{Introdução}

Angola é um país em crescimento, no qual existem diversas dificuldades no acesso a recursos de avaliação e intervenção psicológica. Apesar disso, o incremento do número de licenciaturas e profissionais nesta área é crescente e marcado por uma enorme necessidade de afirmação da ciência psicológica, o que parece conduzir a uma revivência de momentos que se assemelham à inicial abordagem da Psicologia que reduzia quase exclusivamente o psicólogo a um aplicador de testes (Antunes, \& Aparecida, 2012). Nesse sentido, ser psicólogo em Angola pode constituir-se como um grande desafio. Se por um lado, são de fato necessários instrumentos de avaliação validados, por outro, parece imperativo e urgente intervir na prevenção da utilização de rótulos nem sempre positivos, que facilmente podem estigmatizar os clientes em geral e as crianças em particular.

No que se refere à intervenção psicológica na infância, é possível salientar a escassez de profissionais a atuar em contexto escolar em Angola. De fato, ainda não existem psicólogos colocados em quase nenhum ministério da administração pública e os poucos que existem, encontraram o seu lugar em hospitais, onde parecem não ter "mãos a medir" com a quantidade de pedidos. Duma forma geral, o ensino parece encontrar-se ainda em desenvolvimento: continuam a existir escolas do ensino especial (recorde-se que a UNESCO, em 1994, através da Declaração de Salamanca, veio preconizar a inclusão de todas as crianças no ensino regular) e o ensino geral carece de inovação nas práticas educativas, por exemplo, ao nível da igualdade de género (é frequente verificar nas aulas de ginástica orientadas pelos respetivos docentes, os meninos a jogar futebol e as meninas nos arcos, também denominados hula-hoop), entre outras.

Ora, neste contexto, ser docente na área da Psicologia no ensino superior em Angola também parece constituir-se como um outro grande desafio. O que se ensina a futuros psicólogos quando não há testes psicológicos aferidos para a população? E quando os há, como ajudá-los a entender a Psicologia numa perspetiva positiva, a par da consideração dos aspetos negativos do funcionamento humano? Ensinam-se as bases da Psicologia e a capacidade de aprender continuamente atendendo às publicações mais recentes na área. Arriscamo-nos ainda a salientar que, atendendo ao conhecimento fundamentado apenas na experiência profissional adquirida neste país, grande parte dos docentes de Psicologia no ensino superior angolano não são psicólogos e os poucos que o são parecem revelar frequentemente parca experiência no âmbito da intervenção psicológica em contexto real.

Foi com base nestas preocupações que se procurou explorar as potencialidades da prova do Desenho da Figura Humana de Goodenough (1926) como instrumento que poderá constituir uma forma de sensibilizar, por exemplo, os estudantes de Psicologia, nomeadamente os angolanos, para uma abordagem mais abrangente da avaliação infantil, menos rotuladora e mais positiva, permitindo ainda experimentar a sua aplicação num contexto em que os instrumentos adaptados às especificidades culturais da população são escassos.

Da abordagem psicométrica e psicopatológica para uma possível avaliação psicológica infantil assente na Psicologia Positiva

Após a Segunda Grande Guerra Mundial, as consequências ao nível das perturbações e distúrbios psicológicos conduziram os estudos da Psicologia inequivocamente em direção à recuperação e remediação de défices e patologias. Na sequência disso, desenvolveu-se uma abordagem do ser humano baseada, e influenciada, pela doença mental e pelas disfuncionalidades dos sistemas e organizações (Seligman, \& Csikszentmhihalyi, 2000). Foi-se inadvertidamente construindo um enviesamento em direção ao défice, ao negativo e ao menos bem-sucedido da experiência humana (Ágnela Marujo, Miguel Neto, Caetano, \& Rivero, 2007). Segundo Seligman (2002, p. 3), nesta altura, a Psicologia tornou-se numa ciência "quase exclusivamente dedicada a curar pessoas", 
dedicando-se "intensamente à reparação de danos utilizando um modelo da doença do funcionamento humano". Constituiu-se assim "como um mero subcampo das profissões da saúde e transformou-se numa ciência de vitimologia" (Seligman, 2002, p. 4).

Atualmente, esta visão negativa tem vindo a ser substituída por uma atenção mais acentuada aos aspetos positivos do funcionamento humano, nomeadamente no âmbito da Psicologia Positiva. O objetivo da Psicologia Positiva "é operar uma transformação na prática psicológica para que esta mude o seu foco centrado em reparar os aspetos menos positivos da vida das pessoas, para também construir as melhores qualidades da vida" (Seligman, 2002, p.3). O autor refere que a Psicologia não é apenas o estudo da doença, das fraqueza e dos danos, é também o estudo das forças, qualidades e virtudes. Acrescenta que "a psicologia não versa só sobre a doença ou a saúde, mas também sobre a educação, o trabalho, o amor, o crescimento e o brincar" (Seligman, 2002, p. 4). Ressalta-se que, apesar da Psicologia positiva ter as suas raízes nas abordagens humanistas, por exemplo, de Carl Rogers, foi com Martin Seligman, no ano de 2000, que esta começou a ver o seu crescimento.

A aplicação desta perspetiva a diversos âmbitos da Psicologia tem vindo a revelar-se uma tendência atual. Neste sentido, podemos salientar, por exemplo, a sua consideração na Psicologia das Organizações, nomeadamente a importância da "promoção do bem-estar subjetivo e prevenção de situações e insucesso profissional e organizacional" (Fernandes, Martins, Mendes, \& Xavier, 2011, p. 2742). Também no que se refere à Psicologia da saúde, têm vindo a aumentar os estudos sobre a relevância das forças pessoais na superação de quadros clínicos mais ou menos graves (Seligman, \& Csijszentmihalyi, 2000). De uma forma geral, são vários os estudos nas diversas áreas da Psicologia que adotam a proposta de Seligman (2002), na medida em que a compreensão dos aspetos positivos do funcionamento humano é essencial num mundo caracterizado como demasiado exigente em diversas dimensões do dia a dia (Fernandes, \& Ferreira, 2013).

No que se refere à Psicologia Infantil, e partindo da perspetiva da Psicologia Positiva, parece-nos que o desenvolvimento da criança deve ser entendido, não só através da análise do que pode estar menos bem, para assentar sobretudo na identificação e promoção das qualidades, bem como no apoio à facilitação da sua concretização efetiva. Pode-se encarar, assim, a avaliação cognitiva da criança como um procedimento que permite detetar aspetos menos positivos e potenciar a intervenção, mas é necessário que os profissionais reconheçam que o seu trabalho em consulta permitirá sobretudo ampliar as forças e potencialidades do cliente, que devem também ser identificadas. Esta atenção aos aspetos positivos está indissociavelmente relacionada com o fim último da educação, enquanto promotora de desenvolvimento, mais do que remediadora de défices. Neste contexto, a utilização de instrumentos de avaliação junto de crianças, será beneficiada, na nossa perspetiva, se entendida enquanto potenciadora da identificação também de qualidades e forças pessoais, numa abordagem abrangente do funcionamento humano que se traduz num perfil de competências e aspetos menos positivos (mais do que um rótulo), sendo que as primeiras certamente permitirão minimizar os últimos.

Uma abordagem abrangente e positiva ao teste do Desenho da Figura Humana de Goodenough

Na sequência desta valorização crescente da abordagem positiva da Psicologia, e procurando aplicá-la ao contexto da avaliação cognitiva de crianças, nomeadamente no que se refere ao constructo de inteligência entendido numa perspetiva clássica assente na sua quantificação, parece-nos que será possível adotar uma visão mais abrangente e assente na Psicologia Positiva, de uma prova tipicamente utilizada neste âmbito, sem desvirtuar o seu primordial objetivo.

O desenho infantil é, desde há muito, um meio importante de avaliação e intervenção psicológica independentemente de qualquer 
linha de orientação mais ou menos positiva da Psicologia. Esta é uma das principais formas de expressão infantil, que permite avaliar o desenvolvimento da criança a vários níveis. Tradicionalmente foi usado como um meio de avaliação de inteligência (Luquet, 1969), mas qualquer profissional de Psicologia facilmente identifica outros benefícios na utilização deste instrumento, por exemplo, no estabelecimento de uma relação de confiança com a criança ou no âmbito da exploração de questões socioemocionais, morais, linguísticas e psicomotoras. Pode-se também apontar o seu potencial enquanto meio de intervenção, por exemplo, no âmbito da ludoterapia (Marques et al., 2000).

É esta perspetiva abrangente que pensamos que se pode associar à utilização de uma das provas de desenho infantil mais reconhecidas em Psicologia: o teste de Desenho da Figura Humana de Goodenough (1926). Esta autora foi uma das pioneiras na história da Psicologia (Stevens, \& Gardner, 1982), especificamente no que concerne ao estudo de crianças sobredotadas e na adoção de uma perspetiva de life-span na Psicologia do desenvolvimento (Harris, 1959). Em 1925 , lançou o seu primeiro livro intitulado de Measurement of Intelligence by Drawings. Até então, os testes de inteligência não verbais apresentavam características psicométricas débeis e eram demasiado longos na sua aplicação junto das crianças (Weiss, 2013).

O resultado mais frequente destes testes é o Quociente de Inteligência (QI), um termo proposto por Stern em 1912, para representar o nível intelectual determinado pela divisão da idade mental (avaliada por testes psicológicos) pela idade cronológica. Mais tarde, Terman e Merrill (1937) propõem a multiplicação deste valor por 100, a fim de eliminar a parte decimal. A classificação mais utilizada na interpretação deste resultado é a apontada por Wechsler (1991): (a) um QI acima de 127 remete para sobredotação; (b) entre 121 e 147, indica uma inteligência muito acima da média; (c) entre 111 e 120 , revela uma inteligência acima da média; (d) entre 91 e 110, encontra-se uma inteligência média; (e) abaixo destes valores, podemos estar perante situações de défice intelectual mais ou menos profundo/grave.

São várias as provas de avaliação deste constructo, destacando-se neste âmbito o teste de Desenho da Figura Humana de Goodenough (1926) como um meio simples de aferir a inteligência em crianças, sendo reconhecido como um instrumento válido e preciso para se identificar competências verbais, de discriminação visual, entre outras (Marques et al., 2000). De acordo com os mesmos autores, o teste permite avaliar o nível conceptual e o desenvolvimento intelectual da criança através do desenho da figura humana, oferecendo grandes vantagens devido à sua facilidade e simplicidade de administração, caráter lúdico, reduzida influência de fatores culturais e baixo custo de aplicação e avaliação. Em suma, pede-se à criança que desenhe uma figura humana, usando, por exemplo, a seguinte instrução: "Nesta folha vais desenhar uma pessoa. $O$ desenho mais bonito que consigas fazer. Faz o mais bonito que conseguires e demora o tempo que quiseres". A qualidade, detalhes e riqueza do desenho da pessoa serão cotados, resultando uma medida do desenvolvimento intelectual infantil.

Apesar de ser uma das provas mais utilizadas em todo o mundo, verifica-se que o seu estudo psicométrico de aferição à população angolana merece, na nossa perspetiva, investimento empírico. Ainda que sem qualquer pretensão de adaptação deste instrumento à realidade de Angola, pensou-se que seria importante experimentar a sua utilização, numa perspetiva exploratória, de forma a colmatar a lacuna existente e já apontada anteriormente neste trabalho, no que se refere à utilização de instrumentos de avaliação psicológica. Para além desta experimentação, adotou-se uma abordagem mais abrangente e positiva da utilização da prova, como veremos adiante.

\section{Método}

Este trabalho assume-se como um ponto de partida para a reflexão sobre o potencial de utilização da prova do Desenho da Figura 
Humana de Goodenough (1926) numa perspetiva abrangente e positiva, em contexto angolano. Optou-se pela abordagem qualitativa na medida em que se procura a riqueza da informação através do processo indutivo (Coutinho, 2011). Pretende-se compreender e descrever o objeto em estudo, enfatizando-se ideias e não quantidades. Nesse sentido, o método selecionado para esta investigação foi o estudo de caso múltiplo, de cariz descritivo.

\section{Participantes}

Participaram neste estudo seis crianças de nacionalidade angolana (provenientes das cidades de Benguela e Lobito, ambas pertencentes à Província de Benguela), três do género feminino e três do género masculino, com idades compreendidas entre os seis e os 10 anos de idade a frequentar o $1^{\circ}$ ciclo do ensino regular. Trata-se de uma amostra de conveniência, pois foram contactados participantes da rede informal de contactos de estudantes estagiários de Psicologia, a fim de poderem praticar a avaliação psicológica infantil no âmbito da sua formação académica. As características gerais das crianças são apresentadas na Tabela 1 (os nomes utilizados são fictícios).

\section{Instrumentos}

Foi aplicada a versão clássica do teste do Desenho da Figura Humana de Goodenough (1926) e utilizado o Sistema Avaliativo Clássico de Goodenough que consiste em cotar com 1 ponto a presença de elementos constituintes de uma figura humana e com 0 pontos

Tabela 1. Caracterização da amostra.

\begin{tabular}{llccc}
\hline & $\begin{array}{c}\text { Nome } \\
\text { Fictício }\end{array}$ & Idade Sexo & $\begin{array}{c}\text { Ano de } \\
\text { Escolaridade }\end{array}$ \\
\hline Caso 1 & "Maria" & 7 & $\mathrm{~F}$ & $2^{\circ}$ \\
Caso 2 & "Manuel" & 9 & $\mathrm{M}$ & $4^{\mathrm{o}}$ \\
Caso 3 & "Jacinto" & 6 & $\mathrm{M}$ & $1^{\mathrm{o}}$ \\
Caso 4 & "Márcia" & 8 & $\mathrm{~F}$ & $4^{\circ}$ \\
Caso 5 & "Rui" & 6 & $\mathrm{M}$ & $1^{\circ}$ \\
Caso 6 & "Liliana" & 10 & $\mathrm{~F}$ & $2^{\circ}$ \\
\hline
\end{tabular}

a ausência de determinados elementos, de acordo com a folha de cotação fornecida pelo manual do teste (Montenegro, s/d).

Como complemento à aplicação do teste, foi conduzida uma entrevista semiestruturada junto dos familiares, com vista à recolha de uma breve história de vida da criança. Os familiares que se disponibilizaram para a entrevista foram questionados sobre aspetos relacionados com a gravidez e parto, fratria, relação conjugal e parental, o desenvolvimento até ao ingresso na escola, a história escolar e o desenvolvimento da criança no seu meio social (bairro, vizinhos, etc.) e familiar. A pergunta inicial que despoletava a entrevista foi: "Por favor, conte-me a história do/a___ (nome da criança)".

\section{Procedimentos}

Tanto a realização da entrevista semiestruturada, antes da aplicação do teste, quanto a aplicação da prova de desenho, foram implementadas com autorização e participação não só da criança, mas também dos seus responsáveis, no âmbito da realização do trabalho dos estagiários de Psicologia, tendo em vista a sua preparação no âmbito da avaliação psicológica infantil. Os pais ou tutores das crianças foram contactados e foi pedida a sua autorização para a participação dos menores nesta investigação. Cada pai, mãe ou tutor assinou um termo de consentimento informado, tendo sido comunicado o objetivo do estudo e garantidos os direitos de participação voluntária, assegurando-se o anonimato e confidencialidade no tratamento dos dados.

A recolha de dados decorreu em situação individual, no domicílio das crianças, tendo sido pedido aos pais ou tutores que não permanecessem na sala em que estava a decorrer a avaliação. Para a aplicação do teste do Desenho da Figura Humana de Goodenough (1926), foram utilizadas folhas A4 em branco e um lápis. Apenas uma criança insistiu em utilizar lápis de cor e, após alguma persistência, foi permitida a sua utilização, apesar de não estar prevista na aplicação da versão clássica deste 
instrumento de avaliação. Os aplicadores - estudantes de Psicologia - forneceram a instrução simples definida pela autora do instrumento: "Por favor, desenha uma pessoa. Faz o desenho mais bonito que puderes. Demora o tempo que precisares".

\section{Resultados}

\section{Apresentação dos casos em estudo}

\section{Caso 1: "Maria"}

Maria tem sete anos e vive com parentes dos pais, nomeadamente a avó materna. É a sétima filha do casal, que se separou quando a Maria tinha seis meses, ficando esta inicialmente a viver com o pai. Aos nove meses foi hospitalizada por estar em casa sozinha e ingerir petróleo. Nesta altura, a avó materna decidiu cuidar da criança tendo sido afastada da guarda paterna. A avó reportou que tanto a mãe como o pai consumiam álcool excessivamente o que os levou a perder os empregos. Quanto à história de saúde da criança, para além do episódio referido anteriormente, salienta-se que aos dois anos de idade, a Maria fraturou o braço devido a uma queda e que aos quatro anos, numa tentativa de fazer o pino, feriu-se na perna esquerda. No que se refere a aquisições desenvolvimentais, destaca-se que adquiriu a linguagem tardiamente, tendo começado a articular palavras aos quatro anos e oito meses. Ao entrar no sistema de ensino com seis anos, os professores aconselharam o seu ingresso na escola de ensino especial, frequentando atualmente o $2^{\circ}$ ano de escolaridade. Reiniciaram-se os contactos com a mãe aos cinco anos e seis meses e, este ano, aos sete anos de idade, a Maria começou a passar férias com a mãe e com a tia (irmã da mãe).

O teste do Desenho da Figura Humana de Goodenough (1926) foi aplicado à Maria, que demorou 25 minutos a terminar (Figura 1). Face à instrução, a Maria decidiu que preferia desenhar a sua casa e, só depois, é que desenhou a figura humana. $\mathrm{Na}$ exploração do desenho, a Maria referiu ao aplicador do teste que a pessoa que havia desenhado era a sua prima. Confirmou depois que gostava mais de desenhar a escola porque considerava que desenha melhor "as portas e janelas, as salas de aulas e professores". Na continuidade da exploração, a Maria verbalizou: "gosto tanto de passear com a mamã mas só vou quando a avó mandar".

\section{Caso 2: "Manuel"}

O Manuel é uma criança com nove anos de idade que vive com os seus pais biológicos. Tem quatro irmãos e frequenta o $4^{\circ}$ ano de escolaridade. Salienta-se a inexistência de problemas de saúde ou outros relevantes a reportar.

Após a aplicação do teste, e afirmando o Manuel ter terminado, referiu ao aplicador que queria desenhar mais, tendo decidido desenhar também o irmão para além de si próprio (Figura 2). No total, a tarefa teve a duração de aproximadamente 40 minutos. Durante a aplicação mostrou grande interesse e vontade de participar. No final da aplicação, olhou para o desenho sorrindo. Face ao questionamento sobre o fato de desenhar o irmão, comentou que gostava muito de brincar com o mesmo e, mais adiante, afirmou que não desenhou o pai porque o pai "brinca pouco e nunca está em casa" (de notar que o estudante aplicador decidiu depois explorar detalhadamente os elementos presentes no desenho, a criança foi indicando e o aplicador foi registando, como se pode observar no desenho).

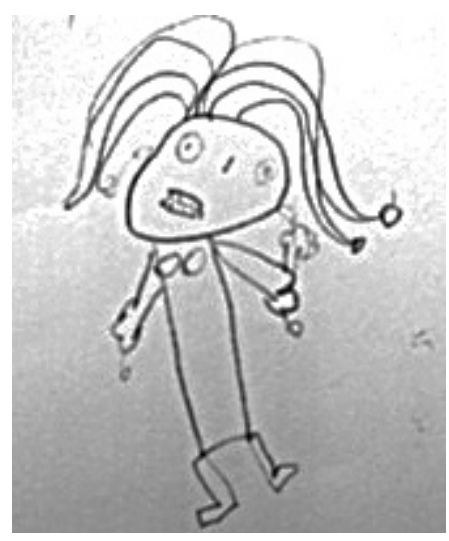

Figura 1. Desenho da Figura Humana da "Maria". 


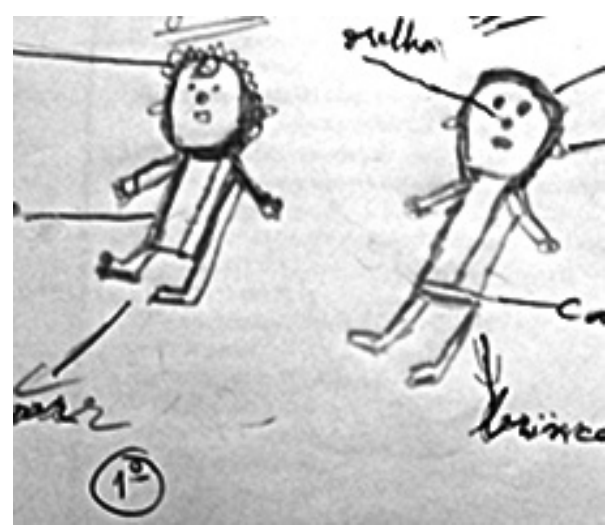

Figura 2. Desenho da Figura Humana do "Manuel".

\section{Caso 3: "Jacinto"}

Jacinto é uma criança de sete anos que ingressou, no ano corrente, na escola de $1^{\circ}$ ciclo. Vive com a mãe, duas irmãs e o seu sobrinho (filho da sua irmã). O pai não assumiu a paternidade. A criança recorrentemente pergunta pelo pai e a mãe usualmente responde que o mesmo está sempre a viajar e um dia voltará. Jacinto afirmou que gostava muito de ler e escrever e que gostava da escola. Na escola, segundo a família, é costume envolver-se em muitas lutas e, quando abordado este assunto, o Jacinto respondeu que "tem de ser, pois os outros meninos abusam de mim". É uma criança que passa grande parte do seu dia na rua, sem horas para refeições ou para entrar em casa. A prática de castigos corporais é comum. O Jacinto afirmou que nestas situações foge para a casa da tia.

Face à aplicação da prova, o Jacinto mostrou-se tímido. Numa primeira fase, iniciou o esboço, mas referiu que não gostava. Afirmou que queria começar de novo. Depois de iniciar o segundo desenho, apresentado na Figura 3, demorou 15 minutos a terminar (tal como no caso anterior, o aplicador foi anotando os elementos presentes de acordo com as indicações da criança).

\section{Caso 4: "Márcia"}

Márcia é uma criança de oito anos, que frequenta o $4^{\circ}$ ano e vive com os pais e 3 irmãos. Teve uma infância saudável e começou a estudar cedo, pois completou o

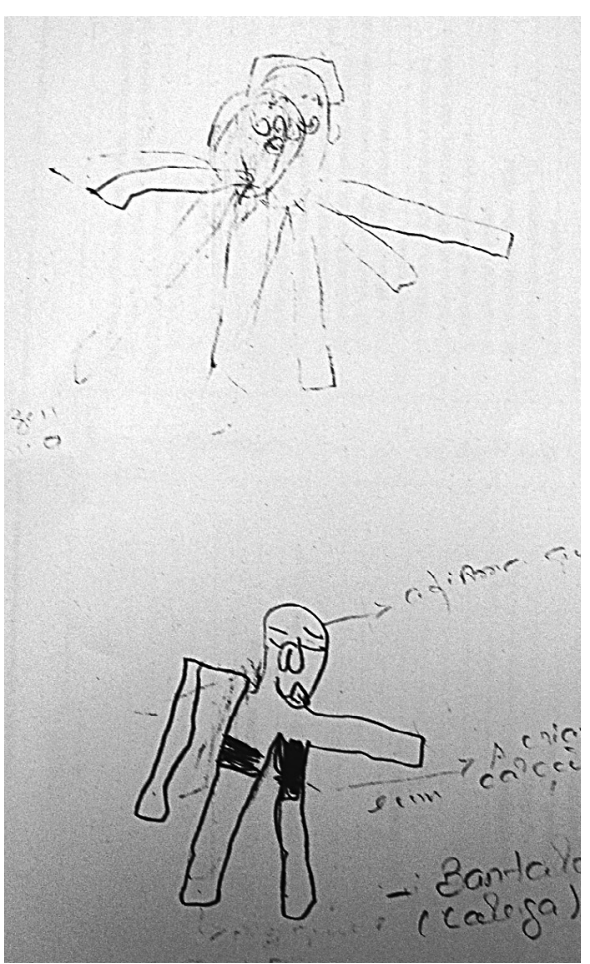

Figura 3. Desenho da Figura Humana do "Jacinto".

$1^{\circ}$ ano com cinco anos de idade. Referiu que gostava de estudar e da professora, profissão aliás, que prontamente afirmou que desejava seguir um dia.

Face ao teste, mostrou alguma timidez inicialmente, sempre tapando a boca com a mão. À medida que o desenho progredia, mostrou-se mais confiante. No final da prova, a Márcia salientou que desenhou uma menina e analisou o próprio desenho, comentando "a boca não está bem" (mostrando um ar triste). Logo em seguida, começou a explicar-se, tentando como que compensar o fator que parecia achar negativo, justificando que tinha desenhado os botões e os bolsos da saia e também os sapatos (Figura 4). Também neste caso o estudante aplicador explorou o desenho anotando não só os elementos presentes, mas também comentários da criança, como se pode observar na figura abaixo.

\section{Caso 5: "Rui"}

Rui é uma criança de seis anos, filho único, que vive atualmente com os seus pais numa 


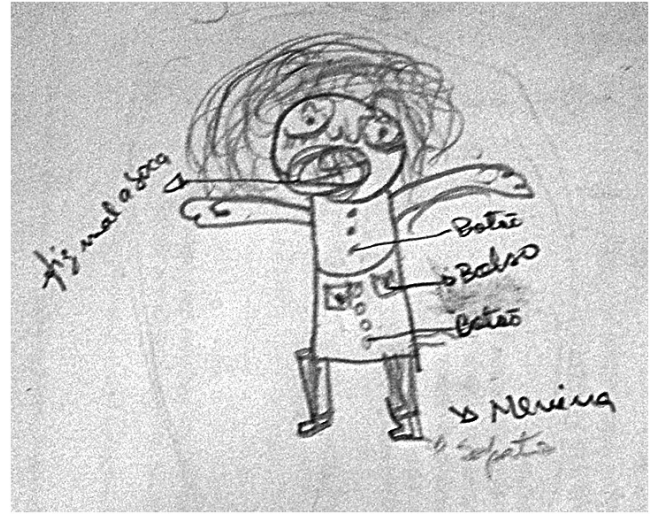

Figura 4. Desenho da Figura Humana da "Márcia".

casa comum de família, onde coabitam avós, tios, primos e outros. Os pais vivem em união de fato e pretendem formalizar o casamento em breve. Tanto a mãe como pai são professores. Viveu uma infância saudável. A transição para o pré-escolar aos 24 meses de idade foi difícil, pois Rui nunca havido estado afastado da mãe, tendo sido marcada por choros e birras durante várias semanas. Foi matriculado em fevereiro e, na altura da aplicação desta prova, havia frequentado o $1^{\circ}$ ano apenas de fevereiro a junho (cerca de $4 / 5$ meses). A família reportou êxito geral na escola, quer ao nível cognitivo quer emocional, bem como uma boa adaptação social.

A aplicação demorou 18 minutos e o Rui encarou esta prova com bastante naturalidade, mostrando-se positivamente emocionado com a experiência. O resultado é apresentado na Figura 5.

\section{Caso 6: "Liliana"}

Liliana é a terceira filha de um casal jovem, fruto de gravidez não planeada. Durante a gravidez, ambos os elementos do casal consumiam álcool e envolviam-se em diversas formas de violência conjugal quer física quer psicológica, segundo relatou a tia, atual tutora da criança. Tanto a gravidez como o parto decorreram normalmente, porém, após o nascimento, Liliana teve inúmeros problemas respiratórios chegando a estar diversas vezes internada. Foi amamentada até aos oito meses de idade, altura em que a

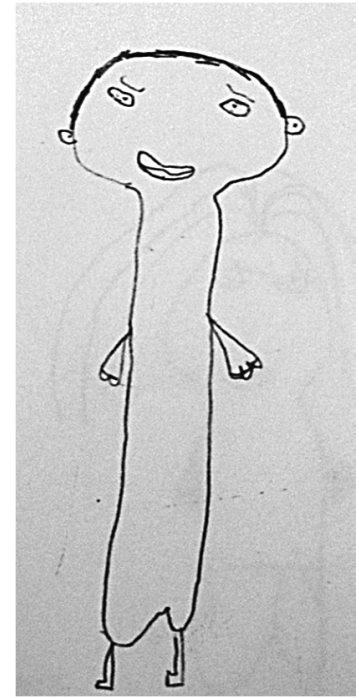

Figura 5. Desenho da Figura Humana do "Rui".

mãe engravidou novamente. Depois da nova gravidez, a criança foi entregue à avó materna, uma vez que a família passava por dificuldades. Porém, segundo relatou a tia, a avó cuidou da Liliana durante alguns anos, mas o seu desenvolvimento estava cada vez mais comprometido. Nas palavras da tia, "a criança era deixada sozinha em casa, e refugiava-se nos cantos". A alimentação era muito débil e a componente afetiva, segundo a mesma fonte, era "completamente esquecida". Há alguns anos a tia decidiu cuidar da criança e trazê-la frequentemente para sua casa, apesar de continuar a viver oficialmente com a avó.

O aspeto físico geral da Liliana aproximava-se ao de uma criança de 5/6 anos, apresentando uma baixa altura para a idade de 10 anos. Frequenta atualmente o $2^{\circ}$ ano, pois tem vindo a ser retida. Manifesta dificuldades em comunicar e revela alguma agressividade para com os pares. Aliás, as outras crianças do bairro chamam-Ihe "burra" e "baixinha", reagindo aos insultos de forma agressiva. A Liliana afirmou que gostava mais de estar na casa da tia, onde brincava com alguns vizinhos com idades aproximadas aos 6 anos de idade.

De notar que, apesar de não confirmado, parece ter havido um motivo para o 
abandono desta criança por parte dos pais (que continuam a cuidar dos outros filhos) relacionado com a possibilidade dos mesmos considerarem que teria algum tipo de défice desenvolvimental. Colocou-se também em hipótese a possibilidade de se tratar de uma criança com Síndrome Fetal Alcoólico (SFA), descrito pela primeira vez em 1968 por Lemoine e colaboradores, uma vez que a mãe consumiu álcool durante a gravidez e alguns comportamentos e défices da Liliana poderão ser assim explicados. No entanto, não existem muitos estudos sobre SFA em África que nos possam ajudar a identificar, por exemplo, as manifestações físicas da síndrome nesta etnia. Em crianças caucasianas foram reportados: olhos pequenos, lábio superior fino, fácies plana, cabeça pequena, hipoplasia do philtrum e/ou do maxilar superior (Lemoine, Harouusseau, Borteyru, \& Menuet, 1968).

Liliana mostrou-se positivamente emocionada com a ideia de fazer um desenho. Apesar de lhe ser dado o lápis, insistiu em usar os seus lápis de cor. Depois da persistência, foi acedido o seu pedido para usar cores. A criança fez o desenho (Figura 6) e perguntou, de imediato, se podia fazer outro.

Pediu para desenhar uma casa e assim o fez. Afirmou que o desenho da figura era ela própria e que a casa era a dela. Durante a exploração, afirmou que tinha saudades dos pais e que eles virão vê-la (os pais vivem noutra cidade e apenas contactam a criança uma ou duas vezes por ano, segundo a tia). O desenho da figura humana foi completado em aproximadamente 20 minutos. Trata-se de um desenho muito pequeno, ocupando apenas um canto da folha com $2 \mathrm{~cm}$ de altura.

\section{Análise dos resultados no teste de Desenho da Figura Humana de Goodenough numa perspetiva abrangente e positiva}

Apesar de não ser esse o principal objetivo, apresentam-se em seguida os resultados

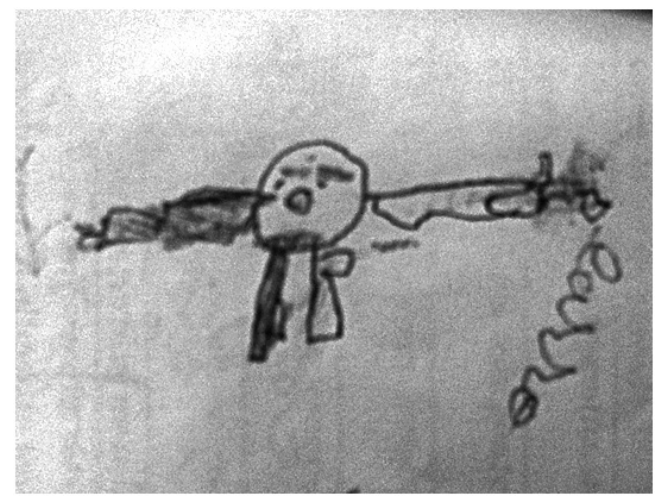

Figura 6. Desenho da Figura Humana da "Liliana".

quantitativos no âmbito da avaliação cognitiva (intelectual) obtidos pelos estudantes de Psicologia na análise dos desenhos produzidos pelas crianças angolanas em estudo. Na Tabela 2 encontram-se os valores finais, após a cotação da prova efetuada por cada aplicador. Foi utilizado o sistema de cotação clássico já referido, que permitem aceder a um QI, calculado através de tabelas portuguesas (Montenegro, s/d). Relembra-se que, dado que não existe qualquer tipo de aferição para a população de Angola, esta é a única abordagem possível. Realça-se que estes resultados não foram utilizados como rótulo na sessão dinamizada pelos estagiários de Psicologia que se seguiu à aplicação do teste (para feedback sobre a avaliação e sugestões de intervenção) ou sequer divulgados aos responsáveis pelas crianças.

Tomando em consideração Wechsler (1991), podemos referir que dois casos apresentam um resultado abaixo de 91 (Casos 2 e 6), três casos entre 91 e 110 (Casos 1, 3 e 4) e um caso acima de 121 (Caso 5). No geral, são os casos 2 e 6 que apresentam um baixo score, o que poderá ser motivo para incentivar os pais e professores a uma mais atenta estimulação cognitiva nestas crianças, sobretudo no que se refere ao Caso 6, embora se acautelem as questões relacionadas com a ausência de aferição para esta população e não realização de treino inter-cotadores. Como não se pretende com este trabalho explorar estes aspetos de natureza quantitativa, optamos apenas por apresentar os resultados a título meramente 
Tabela 2. Resultados de QI obtidos pelas 6 crianças na prova do Teste do Desenho da Figura Humana de Goodenough (1926).

\begin{tabular}{lccccc}
\hline & Nome Fictício & Idade (anos) & Sexo & Ano de Escolaridade & QI apurado \\
\hline Caso 1 & "Maria" & 7 & $\mathrm{~F}$ & $2^{\circ}$ & 104 \\
Caso 2 & "Manuel" & 9 & $\mathrm{M}$ & $4^{\circ}$ & 86 \\
Caso 3 & "Jacinto" & 6 & $\mathrm{M}$ & $1^{\circ}$ & 92 \\
Caso 4 & "Márcia" & 8 & $\mathrm{~F}$ & $4^{\circ}$ & 100 \\
Caso 5 & "Rui" & 6 & $\mathrm{M}$ & $1^{\circ}$ & 125 \\
Caso 6 & "Liliana" & 10 & $\mathrm{~F}$ & $2^{\circ}$ & 60 \\
\hline
\end{tabular}

exemplificativo da possibilidade de aplicação e cotação da prova, sem aprofundarmos mais esta questão.

Atendendo ao objetivo deste trabalho relacionado com a possibilidade de exploração desta prova para além do QI, mas antes assente em aspetos positivos do funcionamento das crianças em estudo, é possível salientar um conjunto de aspetos manifestados pelas mesmas na exploração da prova, sistematizados na Tabela 3, sobretudo no que se refere: à motivação para a tarefa; a interesses manifestados pela criança; a aspetos socioemocionais, linguísticos e vocacionais revelados; bem como à relação estabelecida com o técnico. Algumas dimensões não foram passíveis de análise pois não se encontraram dados explícitos nesse âmbito na descrição dos casos em estudo (surgem com a indicação "sem dados", na referido tabela).

De forma geral, é possível salientar a elevada motivação para a tarefa. Os seis casos em análise reagiram positivamente perante a proposta de realização do desenho, manifestando a sua felicidade e mantendo um elevado nível de atenção durante a realização da prova. Destaca-se, ainda, a possibilidade de identificação de interesses das crianças em relação à sua vida familiar, ao seu contexto escolar ou até no âmbito de atividades de lazer, através da aplicação de uma prova na sua essência centrada no desenvolvimento intelectual traduzido em um QI.

Para além disso, os aspetos de natureza social ou emocional acabaram por ser revelados frequentemente de forma espontânea pelas crianças na exploração do desenho, desde preocupações a sentimentos mais, ou menos, positivos. A utilização da linguagem no momento de exploração do desenho permitiu ao técnico identificar competências ou dificuldades no âmbito da comunicação. Em um dos casos foi possível, ainda que não intencionalmente, registrar aspirações de ordem vocacional.

Finalmente, a análise da possibilidade de construção de uma relação com o técnico, a partir da concretização de uma prova de avaliação cognitiva, permitiu constatar a relevância deste instrumento (aparentemente de natureza lúdica para a criança) na criação de laços de confiança, permitindo a livre expressão emocional através do relato de aspetos íntimos de natureza nem sempre fácil.

À medida que a prova foi aplicada, poderiam ter sido registadas outras informações, por exemplo, no âmbito da psicomotricidade envolvida na tarefa; contudo, o objetivo deste trabalho de caráter exploratório centrou-se, sobretudo, em mostrar que parece ser possível uma abordagem mais abrangente e positiva no âmbito da avaliação através de uma prova como a que foi utilizada neste trabalho.

\section{Discussões, reflexões e sugestões para o futuro}

O objetivo principal deste trabalho era o de verificar a viabilidade de aplicação do teste em crianças angolanas, a fim de colmatar 
Tabela 3. Resultados assentes na perspetiva da Psicologia Positiva e numa abordagem abrangente da prova

\begin{tabular}{|c|c|c|c|c|c|c|}
\hline Caso & $\begin{array}{c}\text { Motivação para a } \\
\text { tarefa }\end{array}$ & Interesses & Aspetos socio-emocionais & $\begin{array}{c}\text { Aspetos } \\
\text { linguísticos }\end{array}$ & $\begin{array}{c}\text { Aspetos } \\
\text { vocacionais }\end{array}$ & $\begin{array}{l}\text { Relação com } \\
\text { o aplicador }\end{array}$ \\
\hline 1 & $\begin{array}{c}\text { Revelou atenção e } \\
\text { mostrou-se feliz por } \\
\text { poder realizar a tarefa }\end{array}$ & Gosta de desenhar & $\begin{array}{l}\text { Gosta de passear com } \\
\text { a mãe mas só pode } \\
\text { quando a avó deixa }\end{array}$ & $\begin{array}{l}\text { Competências } \\
\text { adequadas à } \\
\text { idade }\end{array}$ & Sem dados & Confiança \\
\hline 2 & $\begin{array}{c}\text { Revelou atenção e } \\
\text { mostrou-se feliz por } \\
\text { poder realizar a tarefa }\end{array}$ & $\begin{array}{l}\text { Gosta muito de } \\
\text { brincar com o } \\
\text { irmão }\end{array}$ & $\begin{array}{l}\text { Não quis desenhar o pai } \\
\text { porque brinca pouco e } \\
\text { nunca está em casa }\end{array}$ & $\begin{array}{l}\text { Competências } \\
\text { adequadas à } \\
\text { idade }\end{array}$ & Sem dados & Confiança \\
\hline 3 & $\begin{array}{c}\text { Revelou atenção e } \\
\text { mostrou-se feliz por } \\
\text { poder realizar a tarefa }\end{array}$ & $\begin{array}{l}\text { Gosta de ler, } \\
\text { escrever e da } \\
\text { escola }\end{array}$ & $\begin{array}{c}\text { Não gosta do seu } 1^{\circ} \\
\text { desenho; justifica o seu } \\
\text { envolvimento em lutas e } \\
\text { como reage aos castigos }\end{array}$ & $\begin{array}{l}\text { Competências } \\
\text { adequadas à } \\
\text { idade }\end{array}$ & Sem dados & Confiança \\
\hline 4 & $\begin{array}{c}\text { Revelou atenção e } \\
\text { mostrou-se feliz por } \\
\text { poder realizar a tarefa }\end{array}$ & $\begin{array}{l}\text { Gosta de estudar e } \\
\text { da professora }\end{array}$ & $\begin{array}{l}\text { Timidez no início e um } \\
\text { ar triste quando salienta } \\
\text { falhas no seu desenho }\end{array}$ & $\begin{array}{l}\text { Competências } \\
\text { adequadas à } \\
\text { idade }\end{array}$ & $\begin{array}{l}\text { Quer ser } \\
\text { professora }\end{array}$ & Confiança \\
\hline 5 & $\begin{array}{c}\text { Revelou atenção e } \\
\text { mostrou-se feliz por } \\
\text { poder realizar a tarefa }\end{array}$ & Sem dados & $\begin{array}{c}\text { Positivamente } \\
\text { emocionado com a } \\
\text { experiência do desenho }\end{array}$ & $\begin{array}{l}\text { Competências } \\
\text { adequadas à } \\
\text { idade }\end{array}$ & Sem dados & Sem dados \\
\hline 6 & $\begin{array}{c}\text { Revelou atenção e } \\
\text { mostrou-se feliz por } \\
\text { poder realizar a tarefa }\end{array}$ & $\begin{array}{c}\text { Gosta de estar } \\
\text { na casa da tia e } \\
\text { de brincar com } \\
\text { crianças mais } \\
\text { novas }\end{array}$ & $\begin{array}{l}\text { Explica agressividade com } \\
\text { os pares, revela saudades } \\
\text { dos pais e mostra-se } \\
\text { positivamente emocionada } \\
\text { com o desenho }\end{array}$ & $\begin{array}{l}\text { Dificuldades } \\
\text { de } \\
\text { comunicação }\end{array}$ & Sem dados & Confiança \\
\hline
\end{tabular}

as lacunas no que diz respeito ao acesso a instrumentos estandardizados que possam ser utilizados neste contexto cultural, assumindo-se a sua utilização numa perspetiva abrangente e positiva, menos limitadora e negativamente rotuladora.

Neste sentido, conclui-se que o teste foi muito bem recebido por todas as crianças. Algumas demonstravam tanta alegria face à atividade, que queriam desenhar mais e mais desenhos para oferecer ao estudante de Psicologia, ao professor, aos pais, etc. Esta experiência parece indiciar que os aspetos lúdicos da aprendizagem, nomeadamente através do desenho, podem não estar a ser suficientemente dinamizados com estas crianças nas escolas ou no ambiente familiar. Para algumas, fazer um desenho parecia uma "explosão de felicidade".

De fato, a aplicação desta prova foi bem sucedida, em primeiro lugar, porque permitiu a aplicação de um teste psicológico, reconhecido e validado em inúmeros países (Marques et al., 2000), que teve utilidade no processo de avaliação psicológica envolvido neste trabalho. Duma forma geral, verificou-se que este pode ser um teste útil em Angola, mesmo não tendo recorrido a normas para a população. No entanto, salientamos que, ainda assim, será importante o investimento empírico na sua aferição. Esta foi apenas uma experiência com resultados de caracter descritivo no âmbito de um estudo de caso.

Apesar de todos os debates em volta da noção de QI, esta é das poucas ferramentas passíveis de avaliar a nível psicométrico o desenvolvimento cognitivo destas crianças. Sabemos, contudo, das limitações dos "rótulos" aliados ao QI e temos especial cuidado com isso, principalmente neste contexto em que a Psicologia está ainda a dar os primeiros passos. Por um lado, em Angola, a Psicologia ainda é vista como algo muito recente, por outro, a divulgação que tem tido passa essencialmente 
por uma abordagem de rotulação diagnóstica. Parece-nos que é necessário ajudar a relativizar esta supervalorização da rotulagem na prática da Psicologia neste país e este estudo pode constituir-se como apenas mais um contributo neste âmbito. Relembra-se que os resultados de QI aqui apurados numericamente, não foram divulgados aos responsáveis pelas crianças, mas antes optou-se por uma abordagem de avaliação qualitativa e, principalmente, por uma abordagem assente na Psicologia Positiva, realçando também pontos fortes da criança, como vimos no último quadro apresentado.

Aproveitando uma sessão posterior, tendo como cariz o de uma intervenção psicoeducativa familiar, promoveu-se a sensibilização junto dos familiares para que realizassem mais atividades de desenho com as crianças, mostrando a sua vertente estimulante a nível cognitivo, psicomotor, emocional, entre outros. Foi ainda comunicado que as duas crianças com baixo score, beneficiariam-se com mais estímulos intelectuais e desafios a nível cognitivo (sem contudo, revelar os resultados numéricos de QI) nas suas atividades diárias. Foram salientadas também as competências das crianças reveladas na aplicação do teste atendendo à perspetiva da Psicologia positiva proposta por Seligman (2002). Para além da exploração dos aspetos positivos revelados pelas crianças na realização da prova, a sua aplicação permitiu a construção e consolidação da relação de confiança entre o técnico e a criança, o que nos parece uma mais-valia neste contexto.

Apesar das limitações inerentes a este trabalho, nomeadamente as relacionadas com o instrumento utilizado, não validado para a população alvo, bem como as que se associam às características da amostra, reduzida e de conveniência (embora se trate dum estudo de caso de natureza exploratória e descritiva) ou com a ausência de treino de fidelidade entre os estudantes de Psicologia que aplicaram a prova, o Desenho da Figura Humana de Goodenough (1926) revelou-se, na nossa perspetiva, uma prova que pode ser útil num país como Angola onde, como já referíamos, se verifica uma escassez de provas aferidas e validadas.

Além disso, pode permitir à prática da Psicologia em Angola afastar-se de abordagens demasiado psicométricas e clínicas que não parecem adequar-se numa sociedade cujas oportunidades sociais (escolares, laborais, de lazer, etc.) ainda não são iguais para todos e, logo, qualquer tentativa de "encaixar" as crianças e até mesmo os adultos, em categorias clínicas de desordens patológicas, pode perder por si só o sentido.

Em trabalhos anteriores (Araújo, 2013), procurou-se promover o desenvolvimento dos estagiários e futuros psicólogos angolanos, e este artigo reflete mais um esforço de consolidação da componente prática da formação destes profissionais. No futuro da Psicologia em Angola, é fulcral continuar a investir na adaptação de instrumentos, bem como na replicação de estudos exploratórios como o que se descreveu neste trabalho, utilizando outros instrumentos, noutras faixas etárias e assumindo outras metodologias de investigação, a fim de se poder contribuir para uma abordagem mais abrangente e positiva da prática psicológica neste contexto. 


\section{Patrícia Araújo}

Doutora pela Universidade do Porto. Docente e Investigadora no Instituto Superior Politécnico Jean Piaget, Benguela - Angola.

E-mail: pattaraujo@gmail.com

\section{Rosina Inês Fernandes}

Doutora pela Universidade de Coimbra. Docente e Investigadora no Instituto Politécnico de Viseu, Viseu - Portugal (Cl\&DETS).

E-mail: rosina_ines@hotmail.com

\section{Endereço para envio de correspondência:}

Patrícia Araújo. Rua de S. João,18. CEP: 4740-358 Fão - Portugal.

Recebido: 11/11/2013, Aprovado: 03/07/2015. 
Águeda Marujo, H., Miguel Neto, L., Caetano, A., \& Rivero, C. (2007). Revolução positiva: psicologia positiva e práticas apreciativas em contextos organizacionais. Comportamento Organizacional e Gestão, 13(1), 115-136.

Antunes, M., \& Aparecida, M. (2012). A psicologia no Brasil: um ensaio sobre suas contradições. Psicologia, Ciência e Profissão, 32(n esp), 44-65. doi: 10.1590/S1414-98932012000500005

Araújo, P. (2013). Juan Peatón: una experiencia de intervención para la educación. Revista de la Educación Superior, 41(164), 135-144.

Coutinho, C. (2011). Metodologia de investigação em ciências sociais e humanas: teoria e prática. Coimbra: Almedina.

Fernandes, R., \& Ferreira, J. A. (2013). Um estudo exploratório sobre o bem-estar subjetivo: dimensões sociodemográficas e ocupacionais. In Resumos, $1^{\circ}$ Congresso Internacional de Psicologia, Educação e Cultura (pp. 31). Vila Nova de Gaia: ISPGAYA.

Fernandes, R., Martins, E., Mendes, F., \& Xavier, P. (2011). Satisfação com o trabalho em Educadores Sociais e Professores. In XI Congreso Internacional Galego-Portugués de Psicopedagoxía (pp. 2741-2752). Coruña: Revista Galego-Portuguesa de Psicoloxía e Educación.

Goodenough, F. (1926). A new approach to the measurement of intelligence of young children. Journal of Genetic Psychology, 33, 185-211.

Harris, D. (1959). Florence L. Goodenough, 1886-1959. Child Development, 30, 305-306.

Lemoine, P., Harouusseau, H. Borteyru, J., \& Menuet, J. (1968). Les enfants de parents alcooliques: Anomalies observées, a propos de 127 cas. Ouest Medicine, 8, 476-482.

Luquet, G. (1969). O desenho infantil. Porto: Ed. do Minho.
Marques, S., Pasian, S., Franco, M. Panosso, I., Viana,A., \&Oliveira, D. (2000). Fidedignidade do sistema Goodenough de avaliação cognitiva: uma visão do contexto atual. Estudos de Psicologia (Natal), 7(1), 57-64. doi: 10.1590/S1413-294X2002000100007

Montenegro, A. (s/d). Normas de Avaliação para o teste do desenho da figura humana de $F$. Goodenough (Coleção Textos de Apoio). Coimbra: Faculdade de Psicologia e de Ciências da Educação da Universidade de Coimbra.

Seligman, M. (2002). Positive psychology, positive prevention, and positive therapy. In C. Snyder, \& S. Lopez (Eds.), Handbook of positive psychology (pp. 3-12). Oxford: University Press.

Seligman, M., \& Csikszentmihalyi, M. (2000). Positive psychology: an introduction. American Psychologist, 55(1), 5-14.

Stern, W. (1912). The psychological methods of intelligence testing. Baltimore, III: Warwick and York.

Stevens, G., \& Gardner, S. (1982). Florence Laura Goodenough. In G. Stevens, \& S. Gardner (Eds.), The women of psychology (Vol. 1: Pioneers and innovators, pp. 193-197). Cambridge, MA: Schenkman.

Terman, L., \& Merrill, M. (1937). Measuring intelligence: a guide to the administration of the new revised Stanford-Binet tests of intelligence. Oxford: Houghton Mifflin.

UNESCO (1994). Declaração de Salamanca: sobre princípios, políticas e práticas na área das necessidades educativas especiais. Salamanca: o autor.

Wechsler, D. (1991). Manual for the Wechsler Intelligence Scale for Children - third edition (WISCIII). SanAntonio, TX: Psychological Corporation.

Weiss, A. (2013). Florence Goodenough: 18861959. Consultado em novembro de 2013, de http://www2.webster.edu/ woolflm/ goodenough.html 